\title{
PCBs Content Characteristics in Soil of Changchun City Suburb Vegetable Field
}

\author{
Lei LIU \\ Changchun Institute of Technology \\ Changchun, 130012, China \\ e-mail: llwangjianing@126.com \\ Yanbo XIAO \\ Changchun Institute of Technology \\ Changchun, 130012, China \\ e-mail: siren-xiao@163.com
}

\author{
Yang WANG \\ Northeast Institute of Geography and Agroecology, \\ Chinese Academy of Sciences \\ Changchun, 130102, China \\ e-mail: wangyangw@iga.ac.cn
}

\author{
Ming GAO \\ Changchun Institute of Technology \\ Changchun, 130012, China \\ e-mail: gaoming88@163.com
}

\begin{abstract}
The content and distribution characteristics of 11 kinds of polychlorinated biphenyls (PCBs) in surface soil of Changchun city suburban vegetable field were analyzed. The results showed that the contents of $\mathrm{PCBs}$ in soil were in the range of $27.74 \sim 219.54 \mu \mathrm{g} \cdot \mathrm{kg}^{-1}$, with the average value of 83.75 $\mu \mathrm{g} \cdot \mathrm{kg}^{-1}$, which were in the moderate and unpolluted level. Variation coefficients of PCBs content were larger, indicating that PCBs contents in soil were significantly affected by human activities. The distribution characteristics of PCBs in soil were mainly come from industrial production and influenced by the dominant wind direction of the region. Principal component analysis showed that PCBs in soil were mainly come from transportation, waste incineration and volatile or leakage from paint additive, insulation materials and other industrial products.
\end{abstract}

Keywords- suburban soil; Polychlorinated biphenyls (PCBS); distribution characteristics; pollution sources

\section{INTRODUCTION}

PCBs (Polychlorinated biphenyls, PCBs) are the kinds of biphenyl compounds, atoms of hydrogen connected with carbon on the benzene ring are replaced by chlorine in different degrees [1]. Because of good insulation, thermal conductivity and the inertia, PCBs are widely used in electricity, plastics, chemical and printing industry, etc. Meanwhile, the molecular structure containing benzene ring and chlorine atom caused that PCBs' characteristics of low water solubility, chemical stability and biological toxicity [2], which are liable to accumulate in organisms and give rise to global environmental pollution. As a result, the production and utilization of PCBs had been prohibited in the 1970s, but PCBs in soil could still be detected in many regions, especially in the suburban relatively higher concentration of industrials [3-5]. Changchun city is an important industrial base of northeast China [6], whereas, PCBs residual characteristics in suburban vegetable field soil had not been researched deeply. Soil PCBs in Changchun city suburb vegetable field were taken as the research object to analyze the PCBs contents and sources. The research is of significance to soil pollution prevention and vegetable safety production.

\section{MATERIALS AND MethodS}

\section{A. Sample Collection and Treatment}

In October 2013, fifty surface soil $(0 \sim 20 \mathrm{~cm})$ samples were collected in Changchun city $\left(43^{\circ} 17^{\prime} \sim 44^{\circ} 5^{\prime} \mathrm{N}\right.$, $\left.125^{\circ} 3^{\prime} \sim 125^{\circ} 34^{\prime} \mathrm{E}\right)$ suburbs, with record of position by GPS and the around environmental situation. Each soil sample was acquired by quartering methods from the completely mixed $1.0 \mathrm{~kg}$ soil and then sealed in bags. One part of soil samples were stored under low temperature freezing for determination of PCBs; The other part of the soil samples were air dried at room temperature, grinded through $2 \mathrm{~mm}$ sieves to determine organic matter content and $\mathrm{pH}$.

\section{B. Sample Treatment and Determination}

Weighed $20.0 \mathrm{~g}$ fresh soil (after moisture content measure) and extracted PCBs with the method of acetone/n-hexane. PCBs in the extract liquids were determined through Shimadzu GC-2010 gas chromatograph

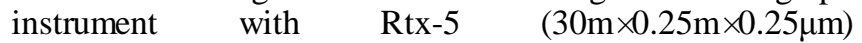
chromatographic column and ECD detector [7]. Interference and system error were controlled by blank sample and parallel determination during analysis, with the parallel sample standard deviation of less than $5.6 \%$ and standard sample addition recovery of $62.7 \%$ 101.2\%.

\section{RESUlts AND Discussions}

\section{A. PCBs Content Characteristics}

As shown in table I, PCBs in Changchun city suburb vegetable soil were detected in different degrees, with the detection rate range of $7.84 \% \sim 100 \%$, among of them, the detection rate of PCB153 was low, and those of PCB28, PCB52 and PCB180 detection rate reached $100 \%$. Coefficients of variation (CV) of PCBs content was in the range of $44.21 \% \sim 366.67 \%$, and with the maximum value for PCB153, which indicated that its contents were significantly affected by human activities [8]. 
Table I Pcbs Components Statistical Characteristic Value Of ChangChun City Suburban Veget able Field Soll

\begin{tabular}{cccccccc}
\hline Homologues & Components & $\begin{array}{c}\text { Detective } \\
\text { rates }(\%)\end{array}$ & $\begin{array}{c}\text { Minimum } \\
\left(\mu \mathrm{g} \cdot \mathrm{kg}^{-1}\right)\end{array}$ & $\begin{array}{c}\text { Average } \\
\left(\mu \mathrm{g} \cdot \mathrm{kg}^{-1}\right)\end{array}$ & $\begin{array}{c}\text { Maximum } \\
\left(\mu \mathrm{g} \cdot \mathrm{kg}^{-1}\right)\end{array}$ & $\begin{array}{c}\text { Standard } \\
\text { deviation }\end{array}$ & $\mathrm{CV}(\%)$ \\
\hline 2Cl-PCBs & PCB8 & 64.71 & 0 & 5.08 & 40.74 & 7.50 & 147.64 \\
\hline \multirow{2}{*}{ 3Cl -PCBs } & PCB28 & 100.00 & 1.37 & 5.22 & 25.93 & 4.76 & 91.19 \\
\hline \multirow{2}{*}{ 5Cl -PCBs } & PCB44 & 74.51 & 0 & 4.02 & 15.34 & 3.84 & 95.52 \\
& PCB52 & 100.00 & 3.09 & 8.29 & 23.35 & 4.04 & 48.73 \\
\hline & PCB101 & 72.55 & 0 & 5.63 & 46.71 & 7.61 & 135.17 \\
& PCB118 & 58.82 & 0 & 3.60 & 27.16 & 5.14 & 142.78 \\
& PCB126 & 31.37 & 0 & 2.99 & 24.51 & 5.48 & 183.28 \\
\hline \multirow{2}{*}{ CCl -PCBs } & PCB138 & 68.63 & 0 & 14.55 & 78.09 & 18.79 & 129.14 \\
& PCB153 & 7.84 & 0 & 0.45 & 8.01 & 1.65 & 366.67 \\
\hline 8Cl -PCBs & PCB180 & 100.00 & 2.29 & 29.88 & 53.67 & 13.21 & 44.21 \\
\hline & PCB198 & 31.37 & 0 & 4.03 & 34.97 & 7.51 & 186.35 \\
\hline
\end{tabular}

PCBs contents were in the range of $27.74 \sim 219.54$ $\mu \mathrm{g} \cdot \mathrm{kg}^{-1}$ and the average content of $83.75 \mu \mathrm{g} \cdot \mathrm{kg}^{-1}$. The toxicity of PCB28, 52, 101, 118, 138, 153 and 180 is bigger than that of others, and thus Soil Environment Quality Standard (Revision) (GB15618-2008) regulated total contents standard of the above 7 kinds of indicative PCBs ( $\left.\sum 7 \mathrm{PCBs}\right)$. $\sum 7 \mathrm{PCBs}$ contents were between the first and second level standard, and most of those closed to the first level standard with the average content of $67.63 \mu \mathrm{g} \cdot \mathrm{kg}^{-1}$, accounted for $80.75 \%$ of total PCBs as shown in Figure 1 . The above results were in accord with the research of PCBs in main industrial area soils of Jilin province by Pan (2011) [6].

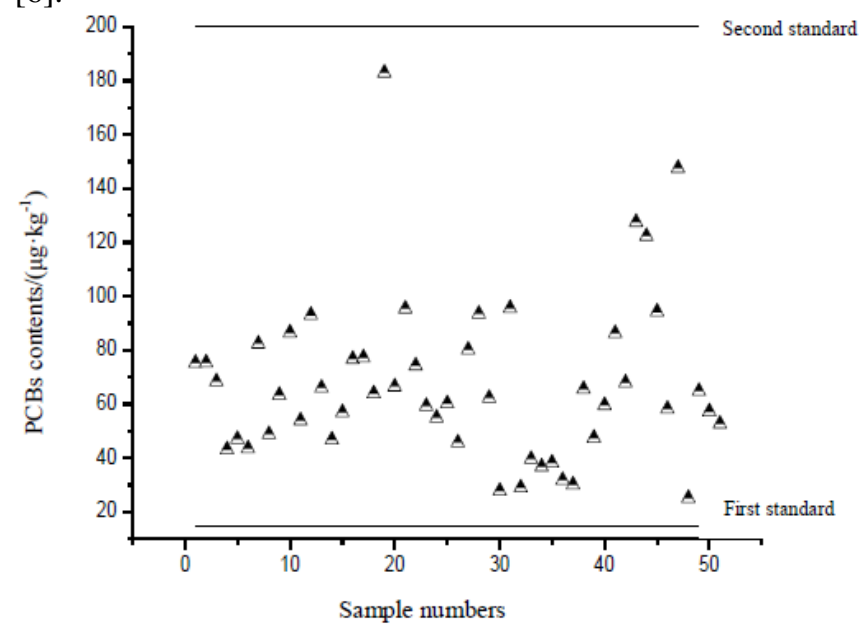

Figure 1. Content characteristic of 7 kinds of indicative PCBs.

\section{B. PCBs Distribution Characteristics in Soil}

The PCBs content distributions in the vegetable field soil of Changchun city suburb were shown in Figure 2. The PCBs distribution figure showed that PCBs high value areas were mainly distributed around the northeastern suburb and around Yitong river bank of southeast suburb of Changchun city, and the highest PCBs content was $219.54 \mu \mathrm{g} \cdot \mathrm{kg}^{-\mathrm{P}}$. The soil PCBs were mainly come from three aspects, which were the plasticizers volatilization, waste incineration and some industrial raw materials leakage [16]. Lots of automobile manufactures, photoelectric enterprises and steel industries distributed in Changchun city could discharge waste water, waste gas and waste residue containing PCBs, and as well as electronic waste and municipal waste incineration also could release PCBs causing soil PCBs pollution. The important reason of high PCBs areas may be that PCBs in the atmosphere could be deposited through dust and rain mostly in the northeast suburban controlled by the southwest dominated wind. Irrigation with river water may be the main reason for the higher levels of PCBs in the vegetable soil around Yitong riverbank. 


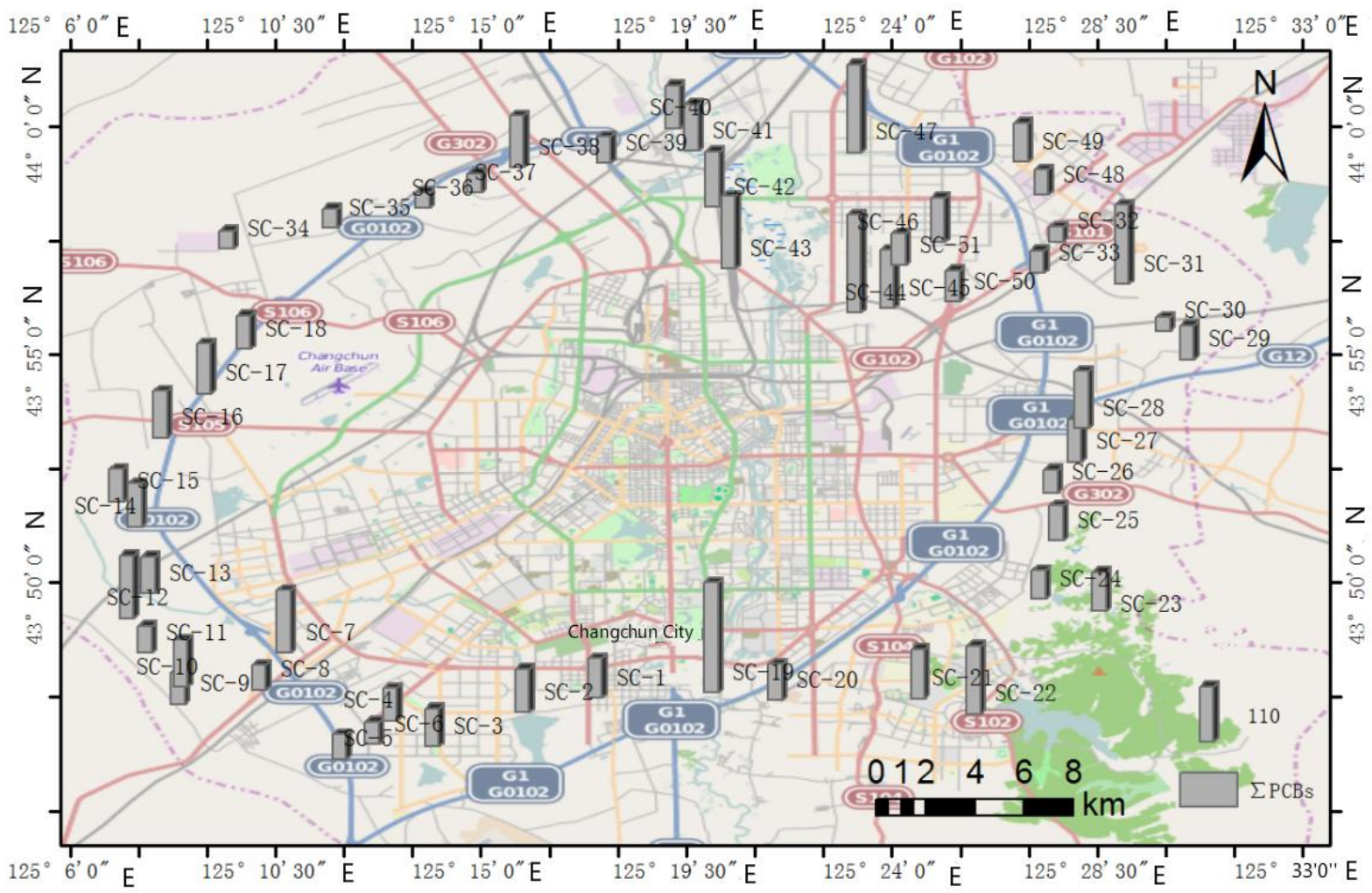

Figure 2. Distribution of PCBs contents in vegetable soils.

\section{PCBs Sources Analysis}

Principal component analysis (PCA) was applied to analyze the main source of vegetable field surface soil PCBs in Changchun city suburb. Factor analyses of PCBs components were conducted and 4 major principle factors were extract which characteristic values were greater than 1 (Table II). The variance contribution rates of four principal components were $35.393 \%, 16.755 \%, 13.616 \%$ and $35.393 \%$ respectively, with a total rate of $76.031 \%$. Rotated component matrix was shown in Table III. The loads of PCB126, PCB198, PCB138, PCB44 were larger (>0.75) in the principal component $\mathrm{F} 1$, and were positively correlated relationship between the homologues, which were mainly come from higher temperature combustion processes (Sun et al., 2013), transportation (such as exhaust, lubricating oil leakage) and waste incineration; The loads of PCB153 and PCB118 were larger $(>0.70)$ in the principal component F2, and were positively correlated relationship between the homologues, which were mainly come from PCBs volatile leakage from the paint additives and insulation materials and other industrial products containing Aroclor1254; The loads of PCB180, PCB52 were larger $(>0.80)$ in the principal component $\mathrm{F} 3$, which were possible come from some certain enterprises, such as cement plant.

The loads of PCB28, PCB101 were larger $(>0.80)$ in the principal component $\mathrm{F}$ 4, which were mainly come from insulation dielectric in electronic power equipments with higher content of Aroclor1242 and Aroclor1248 containing PCBs (Chen et al., 2015)
TABLE II. TOTAL VARIANCE EXPLAINED FOR MAJOR PRINCIPAL COMPONENTS

\begin{tabular}{llll}
\hline & \multicolumn{2}{l}{ Rotated quadratic sum loads } \\
\cline { 2 - 4 } Factors & Total & $\begin{array}{l}\text { Contribution } \\
\text { rates/\% }\end{array}$ & $\begin{array}{l}\text { Cumulative } \\
\text { Contribution } \\
\text { rates } / \%\end{array}$ \\
\hline PC1 & 3.893 & 35.393 & 35.393 \\
PC2 & 1.843 & 16.755 & 52.148 \\
PC3 & 1.498 & 13.616 & 65.765 \\
PC4 & 1.129 & 10.266 & 76.031 \\
\hline
\end{tabular}

TABLE III. ROTATED COMPONENT MATRIX

\begin{tabular}{|c|c|c|c|c|}
\hline \multirow{2}{*}{ Variances } & \multicolumn{4}{|c|}{ Principal components } \\
\hline & $\overline{\mathrm{PC} 1}$ & PC2 & PC3 & PC4 \\
\hline $\begin{array}{l}\text { PCB8 } \\
\text {. }\end{array}$ & 0.404 & -0.373 & 0.124 & 0.219 \\
\hline PCB28 & -0.105 & -0.127 & 0.042 & 0.875 \\
\hline PCB52 & 0.763 & 0.376 & -0.014 & 0.235 \\
\hline PCB44 & 0.0500 & 0.254 & 0.833 & -0.053 \\
\hline PCB101 & 0.222 & 0.271 & 0.001 & 0.837 \\
\hline PCB118 & 0.188 & 0.748 & -0.106 & 0.124 \\
\hline PCB153 & 0.935 & 0.046 & -0.056 & -0.006 \\
\hline PCB138 & 0.814 & 0.496 & 0.024 & 0.069 \\
\hline PCB126 & 0.241 & 0.802 & 0.303 & -0.011 \\
\hline PCB180 & -0.182 & -0.198 & 0.865 & 0.111 \\
\hline PCB198 & 0.848 & 0.076 & -0.245 & -0.113 \\
\hline
\end{tabular}




\section{CONCLUSIONS}

PCBs in Changchun city suburb vegetable soil were detected in different degrees, with the content in the range of $27.74 \sim 219.54 \mu \mathrm{g} \cdot \mathrm{kg}^{-1}$ and the average content of $83.75 \mu \mathrm{g} \cdot \mathrm{kg}^{-1}$. The analysis results showed that the content of PCBs in vegetable soil were in the moderate and unpolluted level. The variation coefficients of PCBs content were larger, which indicated that PCBs distributions in soil were significantly affected by human activities. Principal component analysis showed that the distribution characteristics of PCBs in soil were mainly come from industrial production and influenced by the dominant wind direction of the region.

\section{ACKNOWLEDGEMENTS}

The researches gratefully acknowledge the support of "One-Three-Five" Strategic Planning Principles of Northeast Institute of Geography and Agroecology, Chinese Academy of Sciences (IGA-135-08), and Natural Science Foundation of Jilin Province (20140101003JC).

\section{REFERENCES}

[1] X. Z. Cao, H. G. Chen, S. M. Shen, et al. The nature of PCBs and its harm to the environment. China Sciencepaper online, 3, 375 (2008).

[2] X. L. Zhang, Y. M. Luo, Y. Teng, et al. Residue characters of PCBs in soils of typical polluted areas in Yangtze River delta region. Soils, 41, 588 (2009).

[3] Y. F. Jiang, X. T. Wang, M. H. Wu, et al. Study on pollution characteristics and sources of PCBs in rural areas and suburbs of Shanghai soil. Journal of Agro-environment Science, 29, 899 (2010).

[4] T. Wang, Y. W. Wang, J. J. Fu, et al. Characteristic accumulation and soil penetration of polychlorinated biphenyls and polybrominated diphenyl ethers in wastewater irrigated farmlands. Chemosphere, $\mathbf{8 1}$, $1045(2010)$

[5] W. L. Ma., H. Qi., D. Z. Sun. Study on pollution status of PCBs in the soil of Harbin city. Environmental Protection Science, 34, 67 (2008).

[6] J. PAN, Y. L. Yang, Gai N., et al. Distribution of organochlorine pesticides and polychlorinated biphenyls in multi-media samples in typical industrial and agricultural area of Jilin province. Journal of Agro-environment Science, 30, 2210 (2011).

[7] X. R. Chen, Y. Wang, L.J. Liu, et al. Residues and ecological risk assessment of polychlorinated biphenyls in suburban vegetable soils of Jilin city. Journal of Agro-Environment Science, 34, 1127 (2015).

[8] Q. Liu, J. Wang, Y. X., Shi, et al. Research of soil heavy metal spatial distribution based on GIS. Journal of safety and environment, 7, 109 (2007) 